\title{
Availability, price, and affordability of WHO priority maternal and child health medicine in public health facilities of Dessie, north- East Ethiopia
}

\author{
Abel Demerew Hailu ${ }^{1 *}$ and Solomon Ahmed Mohammed $^{2}$
}

\begin{abstract}
Background: Access to health care is a fundamental human right, and the provision of affordable, high-quality, and appropriate medicines for maternal and child health is a vital component of a well-functioning health system. The study assessed the availability, price, and affordability of WHO priority maternal and child medicines in public health facilities, Dessie, North-East Ethiopia.

Methods: A retrospective cross-sectional study design was conducted in Dessie town from November 2018 to February 2019. A standard checklist adapted from the Logistics Indicator Assessment Tool and WHO/HAl was used to collecting data on the availability, affordability, and price of 45 priority life-saving medicines from eight public health centers and two public hospitals. Descriptive statistics (percent and median) were computed for availability and prices. Affordability was reported in terms of the daily wage of the lowest-paid unskilled government worker.

Results: Twenty-two medicines were not found at all in public health facilities. The overall availability of WHO priority maternal and child medicines was 34.02\%. The mean number of stock-outs was 3.9, and the mean number was 128.9 days. The mean average point availability was 33.5\%, and 7 medicines stock out on the days of assessment. From WHO priority maternal and child medicines, 4 (40\%) of the products were unaffordable and 5 (55.5\%) had higher prices than international prices. Ceftriaxone $1 \mathrm{~g}$, ceftriaxone $500 \mathrm{mg}$, and hydralazine $20 \mathrm{mg}$ injection required wages of $6.58,8.01$, and 5.02 to cover specific maternal health problems respectively. The median price ratio of priority lifesaving maternal and child medicines in public health facilities ranged from 0.65 to 3.19.

Conclusions: The average mean period and point mean availability was very low. The available products were encountered with a high number of stock-outs and unaffordable. The strict control of inventory is recommended to have a steady supply of these essential medicines and improve the quality of health services.
\end{abstract}

Keywords: Availability, Affordability, Price, Medicines, Maternal, And child

\footnotetext{
* Correspondence: Demerewabel@yahoo.com

${ }^{1}$ Department of Pharmacy, Dessie Health Science College, Dessie, Ethiopia

Full list of author information is available at the end of the article
}

C C The Author(s). 2020 Open Access This article is licensed under a Creative Commons Attribution 4.0 International License, which permits use, sharing, adaptation, distribution and reproduction in any medium or format, as long as you give appropriate credit to the original author(s) and the source, provide a link to the Creative Commons licence, and indicate if changes were made. The images or other third party material in this article are included in the article's Creative Commons licence, unless indicated otherwise in a credit line to the material. If material is not included in the article's Creative Commons licence and your intended use is not permitted by statutory regulation or exceeds the permitted use, you will need to obtain permission directly from the copyright holder. To view a copy of this licence, visit http://creativecommons.org/licenses/by/4.0/ The Creative Commons Public Domain Dedication waiver (http://creativecommons.org/publicdomain/zero/1.0/) applies to the data made available in this article, unless otherwise stated in a credit line to the data. 


\section{Background}

Maternal and child health $(\mathrm{MCH})$ focuses on the determinants, mechanisms, and systems that promote and maintain the health, safety well-being, and appropriate development of children and their mothers in communities and societies to enhance the future health and welfare of society and subsequent generations [1]. Accessing essential medicines that satisfy the priority health care needs of the population is the backbone of the health care and well-being of individuals and populations [2].

The United Nations Population Fund and World Health Organization (WHO) launched the global list of priority medicines for mothers based on a global burden of disease and the evidence of efficacy and safety for preventing or treating maternal, newborn, and child mortality and morbidity [3].

The estimated global spending on health will increase from 9 to 21 trillion United States dollars in 2014 to 24 to 24 trillion United States dollars in 2040 [4]. However, lack of access to essential medicines for $\mathrm{MCH}$ remains a major challenge in many developing countries, where more than half of their populations lack access to essential medicines [5]. This will inevitably constrain efforts to reduce mortality and improve the health of children and mothers [6].

Nearly 4.7 million mothers, newborns, and children die each year in sub-Saharan Africa [7], 1.2 million babies die before they reach one month of age and $3.1 \mathrm{mil}-$ lion children who survived their first month of life die before their fifth birthday [8]. The mortality of underfive children was 6.3 million in 2013, around 15, 11, and $7 \%$ of them were caused by pneumonia, diarrhea, and malaria, respectively, [9]. Ethiopia is one of the subSaharan countries with high rates of maternal and child mortality [10].

Early diagnosis and treatment with simple antibiotics could avert as many as 600,000 deaths in cases of pneumonia, whereas improving access to oral rehydration salt (ORS) would save as many of 1.3 million children die annually from diarrhea [9]. The provision of affordable, high-quality, and appropriate essential medicines is a vital component of a well-functioning health system [11] to counteract any existing barriers that might hinder medicine access [12]. Nearly 10 million lives could be saved by improved access to essential medicine [13].

In Ethiopia, pharmaceutical product availability was found to be weak, which suggests that supply chain factors may adversely affect the outcomes of $\mathrm{MCH}$ programs [14]. Accepting and application of $\mathrm{MCH}$ care policy as a general does not minimize the mortality rate of vulnerable groups due to the absence of medicines. Although few studies have been conducted, the WHO/ HAI survey recommends the methodology to be applied at the state or provincial level.

\section{Methods}

\section{Study area and period}

A study was conducted from November 2018 to February 2019 in the public health facility of Dessie town, Ethiopia. Dessie is a town located in the Amhara region of northeast Ethiopia, $400 \mathrm{~km}$ away from Addis Ababa. The total population of the town is estimated to be 151 , 094 among this, 78,203 are females [15]. In Dessie town, there are 8 public health centers, one referral hospital, and district hospital serving for Dessie town and the surrounding nearly 8 million people.

\section{Study design}

A cross-sectional study was conducted in public health facilities in Dessie town. Data were retrospectively abstracted from the bin card, stock card, and health commodity management information system.

\section{Selection of healthcare facilities}

The drug outlets were selected according to the WHO/ Health Action International (HAI) methodology, which has been validated to select a representative sample [9]. All public health facilities which are found in Dessie town were included in this study.

\section{Selection of medicines}

All medicine surveys in this study were taken from the list of "priority life-saving medicines for women and children" developed by the WHO [16]. The WHO had chosen the medicines according to the global burden of the diseases and the evidence of efficacy and safety for preventing or treating major causes of maternal and child mortality and morbidity. Only registered global or regional core medicine was included in the survey. If a medicine was registered, but the stated dosage form or strength differs from that on the global/regional core list, removed the core medicine from the list and alternate form and/or strength to the supplementary list of medicines was added. Moreover, when a therapeutically equivalent medicine was widely used in addition to or instead of a medicine on the global or regional core list, the medicine was added to the supplementary list.

The recommended priority life-saving medicines for mothers are oxytocin, sodium chloride, ringer lactate injectable, and misoprostol tablets for post-partum hemorrhage; magnesium sulfate Calcium gluconate injection, hydralazine, and methyldopa tablets for severe pre-eclampsia and eclampsia; ampicillin, gentamycin, and metronidazole injectables for maternal sepsis; mispristol+mifepristone tablets for provision of safe abortion services and/or the management of incomplete abortion and miscarriage; azithromycin, cefixime capsule, and benzathine benzylpenicillin injectable for sexually transmitted infections; nifedipine 
capsule, dexamethasone and betamethasone injectables for management of preterm labor.

The recommended priority life-saving medicines for children under five are artemisinin combination therapy, rectal artesunate and artesunate injectable for malaria; zinc sulphate dispersible tablets and ORS sachets for diarrhea; amoxicillin (capsule), ampicillin, ceftriaxone, and gentamycin (powder for injections) for treatment of pneumonia; morphine injectable, oral liquid and granules, paracetamol, and procaine benzylpenicillin (powder for injections) for neonatal sepsis.

\section{Data collection tools and procedures}

Data were collected by trained druggist using a standard checklist adapted from the Logistics Indicator Assessment Tool (LIAT) and WHO/HAI second edition [10]. The availability of the priority medicines in their WHOrecommended strengths and dosage formulations was assessed through physical identification in the stores and dispensaries. The pharmacy technicians were also asked to choose the reasons for stock out of medicines. The principal investigators coordinated the data collection process.

\section{Data processing and analysis}

Data were edited and analyzed using Microsoft Excel 2010. Medicine availability was calculated as percent availability of individual medicines, mean average percent, availability across a group of medicines, and variations between sectors. Gelders S et al. (2006) described the availability of medicines in public healthcare facilities and the ranges were: $<30 \%, 30-49 \%, 50-80 \%$, and $>80 \%$ for very low, low, fairly high, and high availability, respectively, [17].

Price and availability results were analyzed for individual medicines. Point availability was determined by the number of medicines available at time of data collection divided by the total number of medicines surveyed multiplied by hundred. Period availability was calculated by dividing the number of days the medicine available by the review period multiplied by hundred. Median Price Ratio (MPR), the ratios relative to a standard set of international reference prices calculated using the median local unit price divided by the international reference unit price. The ratio is thus an expression of how much greater or less the local medicine price than the international reference price [10]. The local currency value at the day of data collection was converted to Dollar. The medicine prices were obtained from the medical price guide issued by management science for health [18]. The ideal value for MPR was used to represent acceptable local price ratios developed by Gelders $S$ et al. for retail patient prices in the public sector (MPR $\leq 1.5)$ [17].
The affordability of treating key health problems using standardized treatment regimens was calculated using the median prices collected during the survey. The treatment cost for an episode of illness is compared to the daily wage of the lowest-paid unskilled government worker to determine the number of days' wages needed to pay for the cost of treatment [10]. This was done by first calculating the daily wage of the workers at the time of data collection. The formula used to calculate affordability is the total cost of medicine times thirty divided by the smallest salary unskilled government worker [19].

The total costs of medicine for the complete duration of treatments for each disease were determined and converted to daily wages. According to Robertson J (2009) criteria, medicines that cost less than a day wage were considered affordable, and those medicines with a cost greater than or equal to a day wage were considered unaffordable [20].

\section{Operational definitions}

- Availability: The percentage of medicine outlets where a particular medicine was found on the day of the survey (point availability) and the last 6 months (period availability).

- Stock out: The frequency and duration of usable stocks unavailability in the store or a balance of zero on the stock records.

- Affordability: It is priced reasonably and the ability to lowest-paid unskilled government workers to pay for the cost of treatment.

- Median price ratio: Ratio of median retail price with the international price set by management science for health.

\section{Results}

Ten public health facilities ( 2 hospitals and 8 health centers) were included in this study. In all health facilities, the responsible person for managing priority medicines was a pharmacy technician and $9(90 \%)$ did not receive training in logistics. Averages mean years working experience store man position and at that, public health facility was 0.96 and 1.6 years, respectively.

\section{Availability of $\mathrm{MCH}$ priority medicines}

In this study, the overall mean availability of WHO prioritizing $\mathrm{MCH}$ medicines in the past 6 months was $34.02 \%$ (Fig. 1). From the overall medicine, 22 medicines were not found at all in public health facilities. These were ampicillin injection $250 \mathrm{mg}$, ORS sachets of $200 \mathrm{ml}$ appropriate flavor, artemisinin combination therapy, artesunate rectal 50-200 mg, procaine benzylpenicillin injection $1 \mathrm{~g}$, morphine with different strength, paracetamol flexible oral solid dosage forms, misoprostol $200 \mu$, 


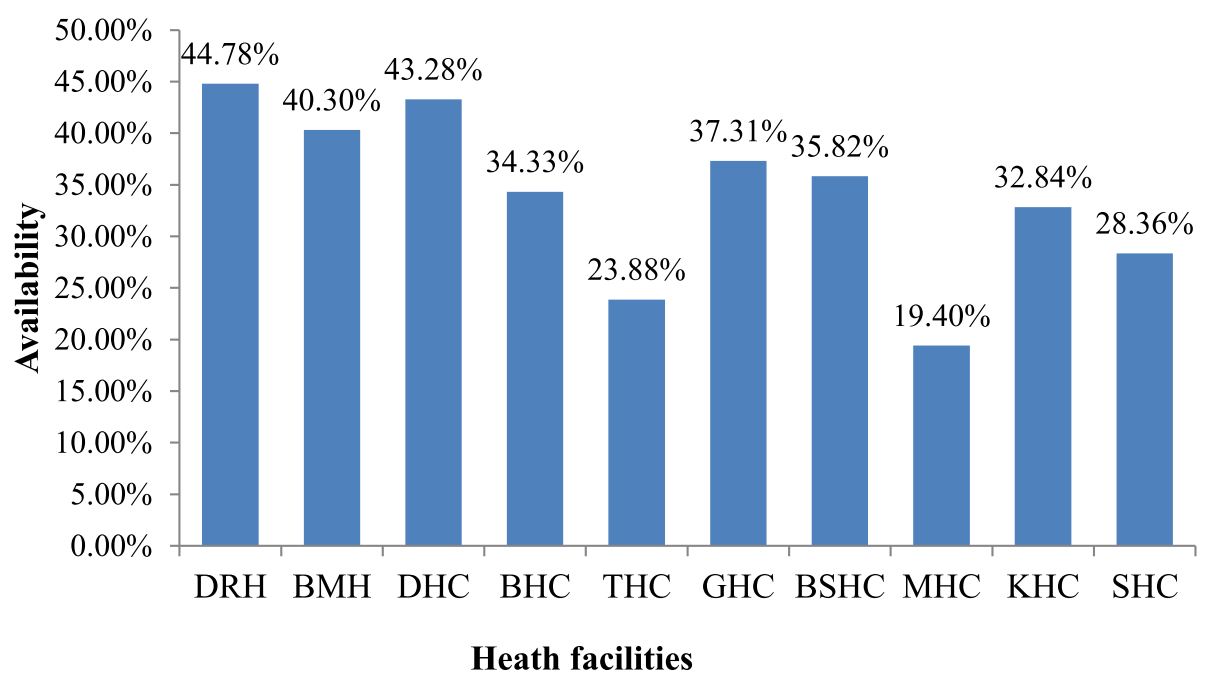

Fig. 1 Availability of WHO priority maternal and child medicines in public health facilities, Dessie, Ethiopia

azithromycin oral liquid $200 \mathrm{mg} / 5 \mathrm{~mL}$, cefixime $400 \mathrm{mg}$, benzathine benzylpenicillin injection $900 \mathrm{mg}$, benzathine benzylpenicillin injection $1.44 \mathrm{~g}$, betamethasone injection $6 \mathrm{mg} / \mathrm{mL}$, medroxyprogesterone acetate, and artemsinin combination therapy.

The individual prioritizes medicine period availability in the past 6 months ranges from 10 to $100 \%$. Pediatric vaccines $100 \%$ and amoxicillin dispersible scored tablets $500 \mathrm{mg}$ and azithromycin $500 \mathrm{mg}$ were available at 100 and $10 \%$, respectively, (Table 1 ).

The mean point availability of $\mathrm{WHO}$ prioritizes $\mathrm{MCH}$ medicines in the overall health facility was $33.5 \%$ (range from 19.4 to $40.3 \%$ ) (Fig. 2). On the day of the assessment, 7 medicines were stock-outs in the overall public facility, these are ampicillin $500 \mathrm{mg}$ injection, ceftriaxone $1 \mathrm{~g}$ injection, ceftriaxone $500 \mathrm{mg}$ injection, sodium chloride injectable solution, methyldopa $250 \mathrm{mg}$ tablet, female condoms, and ringer lactate solution.

The overall public health facilities' average mean the number of stock-outs was 3.9 , and the number of stockout days was 128.9 in the 6 months (Fig. 3).

The stock out medicines at the period during data collection were ampicillin injection $500 \mathrm{mg}$, ceftriaxone $500 \mathrm{mg}$ injection, ceftriaxone $1 \mathrm{~g}$ injection, and barrier methods of contraception (e.g., condoms) were not available in public health facilities (Table 2).

\section{Affordability of $\mathrm{MCH}$ medicines}

The wages required to purchase the standard treatment for severe pneumonia with ceftriaxone $1 \mathrm{~g}$ injection and post-partum hemorrhage with oxytocin was 8.01 and 0.38 days wages to pay for the treatment required for unskilled government worker income (960) birr, respectively, (Table 3).

\section{Price of MCH medicines}

The median price ratio of priority lifesaving $\mathrm{MCH}$ medicines in public health facilities ranged from 0.65 to 3.19. For amoxicillin $250 \mathrm{mg}$ dispersible scored tablets and ORS sachets of 1-l appropriate flavor were 0.65 and 3.19, respectively, (Fig. 4).

Amoxicillin dispersible $250 \mathrm{mg}$ 1(10\%), calcium gluconate injection $100 \mathrm{mg} 2(20 \%)$, gentamicin injection 40 $\mathrm{mg} / \mathrm{ml}(20 \mathrm{mg} / \mathrm{mL}) 5(50 \%)$, implantable contraceptives estradiol cypionate + medroxyprogesterone acetate $2(20 \%)$, depot injection $150 \mathrm{mg} / \mathrm{mL}$ in $1-\mathrm{mL}$ vial $1(10 \%)$, hydralazine injection $20 \mathrm{mg} 2(20 \%)$, magnesium sulfate injection $500 \mathrm{mg} / \mathrm{mL} 1(10 \%)$, and methyldopa tablet 250 mg $1(10 \%)$ was found a surplus of before resupply in public health facility.

Health professionals working in public health facilities pinpointed the reason for stock-outs of priority lifesaving $\mathrm{MCH}$ medicines and pharmaceutical fund supply agencies did not supply adequate products 9 (90\%), wastage due to the expiry of products $6(60 \%)$ and lack of information about $\mathrm{MCH}$ medicines $3(30 \%)$ were the stated reasons.

\section{Discussion}

Universal health coverage is a comprehensive health system approach that facilitates a wide range of health services and significantly improves the life expectancy of patients [23]. Medicines are an essential component of healthcare delivery in any country. In developing countries, equitable access to safe and affordable medicines is crucial to the health and well-being of people. Despite progress made so far in the areas of public health, medicines remain the single most vital factor in the maintenance of health and the treatment of diseases [24]. 
Table 1 Medicines available at public health facilities in the past 6 month, Dessie, Ethiopia

\begin{tabular}{|c|c|c|}
\hline No & List of $\mathrm{MCH}$ medicines & Availability \\
\hline 1 & Amoxicillin: dispersible, scored tablets $250 \mathrm{mg}$ & $90 \%$ \\
\hline 2 & Amoxicillin: dispersible, scored tablets 500 mg & $10 \%$ \\
\hline 3 & Ampicillin: powder for injection 500 mg & $40 \%$ \\
\hline 4 & Ceftriaxone: powder for injection $1 \mathrm{~g}$ & $100 \%$ \\
\hline 5 & Ceftriaxone: powder for injection 500 mg & $60 \%$ \\
\hline 6 & Ceftriaxone: powder for injection $250 \mathrm{mg}$ & $10 \%$ \\
\hline 7 & Gentamicin: injection 40 mg/ml(20 mg/mL) & $90 \%$ \\
\hline 8 & Oxygen: medicinal gas & $20 \%$ \\
\hline 9 & ORS sachets of $500 \mathrm{ml}$ and 11 , appropriate flavor & $10 \%$ \\
\hline 10 & ORS sachets of 11 , appropriate flavor & $80 \%$ \\
\hline 11 & Zinc: 20 mg scored dispersible tablet & $60 \%$ \\
\hline 12 & Artesunate: injection dosage forms 50-200 mg & $10 \%$ \\
\hline 13 & $\begin{array}{l}\text { Lamivudine + nevirapine + zidovudine - } \\
\text { tablet } 30 \mathrm{mg}+50 \mathrm{mg}+60 \mathrm{mg}\end{array}$ & $40 \%$ \\
\hline 14 & Vitamin A: capsule $100,000 \mathrm{IU}$ strength & $50 \%$ \\
\hline 15 & Vitamin A: capsule 200,000 IU Strength & $10 \%$ \\
\hline 16 & Morphine: granules injection $10 \mathrm{mg} / \mathrm{mL}$ & $10 \%$ \\
\hline 17 & Oxytocin: injection $10 \mathrm{IU}$ in $1 ? \mathrm{ml}$ ampoule & $90 \%$ \\
\hline 18 & Sodium chloride: injectable solution $0.9 \%$ isotonic & $80 \%$ \\
\hline 19 & $\begin{array}{l}\text { Sodium lactate compound: injectable } \\
\text { (Ringer's lactate) }\end{array}$ & $80 \%$ \\
\hline 20 & $\begin{array}{l}\text { Magnesium sulfate: injection } 500 \mathrm{mg} / \mathrm{ml} \text { in } 10 \mathrm{~mL} \\
\text { Ampoule }\end{array}$ & $50 \%$ \\
\hline 21 & $\begin{array}{l}\text { Calcium gluconate injection: } 100 \mathrm{mg} / \mathrm{ml} \text { in } 10 \mathrm{~mL} \\
\text { ampoule }\end{array}$ & $40 \%$ \\
\hline 22 & Hydralazine: powder for injection 20 mg & $50 \%$ \\
\hline 23 & Methyldopa: tablet $250 \mathrm{mg}$ & $30 \%$ \\
\hline 24 & Metronidazole: injection $500 \mathrm{mg}$ & $20 \%$ \\
\hline 25 & $\begin{array}{l}\text { Mifepristone + misoprostol: tablet } 200 \mathrm{mg}+ \\
\text { tablet } 200 \text { micrograms }\end{array}$ & $10 \%$ \\
\hline 26 & Azithromycin: capsule 250 mg & $10 \%$ \\
\hline 27 & Azithromycin: capsule 500 mg & $10 \%$ \\
\hline 28 & Nifedipine: immediate release capsule 10 mg & $20 \%$ \\
\hline 29 & Dexamethasone: injection $4 \mathrm{mg}$ & $30 \%$ \\
\hline 30 & Tetanus vaccine & $60 \%$ \\
\hline 31 & Oral contraceptives (pack of 2) & $70 \%$ \\
\hline 32 & $\begin{array}{l}\text { Intrauterine devices and barrier methods of } \\
\text { contraception(e.g. condoms) }\end{array}$ & $40 \%$ \\
\hline 33 & $\begin{array}{l}\text { Implantable contraceptives estradiol cypionate } \\
+ \text { medroxyprogesterone acetate }\end{array}$ & $60 \%$ \\
\hline 34 & $\begin{array}{l}\text { Efavirenz } 600 \text { mg + lamivudine300mg + tenofovir } \\
300 \mathrm{mg}\end{array}$ & $70 \%$ \\
\hline 35 & Artemether - Lummefantrine & $20 \%$ \\
\hline 36 & Artesunate: injection dosage forms 50-200 mg & $20 \%$ \\
\hline 37 & Chloroquine $250 \mathrm{mg}$ & $10 \%$ \\
\hline 38 & Oral polio vaccine & $100 \%$ \\
\hline
\end{tabular}

Table 1 Medicines available at public health facilities in the past 6 month, Dessie, Ethiopia (Continued)

\begin{tabular}{lll}
\hline No & List of $\mathbf{M C H}$ medicines & Availability \\
\hline 39 & Bacille Calmette-Guérin & $100 \%$ \\
40 & Pneumococcal conjugate vaccine & $100 \%$ \\
41 & Measles vaccine & $100 \%$ \\
42 & Tetanus Toxoid Vaccine & $100 \%$ \\
43 & Penta Valent & $100 \%$ \\
44 & Intractable Polio vaccine & $100 \%$ \\
45 & Rotavirus vaccine & $100 \%$ \\
\hline
\end{tabular}

In this study, the overall mean period availability of the WHO prioritized $\mathrm{MCH}$ medicines in public health facilities in the past 6 months was $34.02 \%$. These findings were similar to the study conducted by Abrha (2018), where the availability of priority life-saving was $34.1 \%$ [25]. This is also consistent with a study conducted by Sautenkova N et al. (2012) [26].

According to Gelders S et al. (2006) criteria, [17] the present finding was very low. Lower periodic availability was also reported as compared to a study done by Prinja $S$ et al. (2015) in India, where the overall mean availability of medicines was 45.2 and 51.1\% Punjab and Haryana, respectively, [27]. In the Republic of Moldova, the mean availability in the public sector was $51.2 \%$ [28] and $46 \%$ mean availability was reported in Guatemala by Anson et al. (2012) [29].

The variations in the availability of WHO priority $\mathrm{MCH}$ medicines among studies might be due to poor inventory management systems and inadequate allocation of funds to health facilities to purchase sufficient amounts of $\mathrm{MCH}$ medicines. Financial constraints or inefficient budget utilization for the treatment of chronic and acute conditions and the absence of dollar currency to purchase vital medicines from outside countries have more worsen problems in medicine availability in the health sector.

The government also does not allocate sufficient funds to mobilize $\mathrm{MCH}$ care services and neglect such services to non-governmental organizations to facilitate the program, which creates a question on a mandate for the unavailability of medicines. Although priority lifesaving drugs are used for the treatment of various diseases conditions in children and adults [30], many deaths were due to conditions that could be prevented or treated with access to vital medicines at public health facilities [31]. Health insurance coverage and the package of services covered by health insurance plans were shown to increase the affordability of a vast portion of the medical goods and services that are commonly paid for out-of-pocket expenditure [32]. 


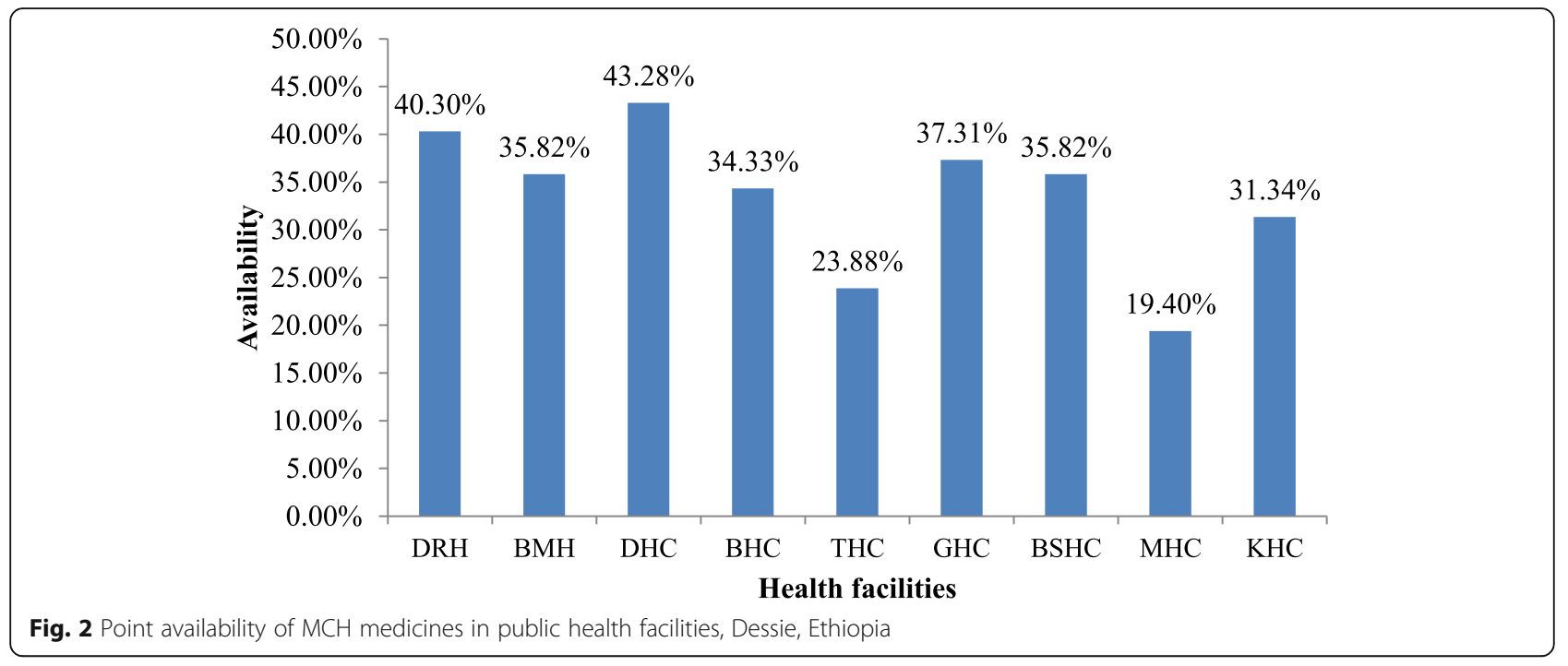

Medicines such as cefixime $400 \mathrm{mg}$, betamethasone injection $6 \mathrm{mg} / \mathrm{mL}$, medroxyprogesterone acetate, and artemsinin completely absent in public health facilities. This was similar to the absence of essential medicines in the northern part of Ethiopia [25]. This might be due to the longer time required to update newly emerging WHO priority medicines to treatment guidelines at the country level and letter in the hospital and health center level. The absence of a legal accusation system for the non-availability of WHO priority $\mathrm{MCH}$ medicines is also the claimed reason.

In this study, the overall public health facility average mean number of stock-out days was 128.9 over 6 months. A high number of stock-out days as compared to the study conducted by Fentie (2015) in Gondar (30.5 days) [33] and lower than Kibira (2017) study 13 reproductive, maternal, newborn, and child health commodities and stock-outs ranged from 14 days [34]. This difference might be attributed to poor stock management, quantification, and procurement practices.
The mean average number of stock out was 2.29 , and once for individual drugs like oxytocin injection and amoxicillin dispersible tablets $250 \mathrm{mg}$ which is lower (9.1) compared to the stock-outs of essential health products in Mozambique and for drugs such as oxytocin, the number of stock out was 2.6 at the district level [35]. This finding also lower than that done by Getahun et al. (2015), where amoxicillin $250 \mathrm{mg}$ scored dispersible tablets number of a stock-out was 33 [36]. This might be due to differences in the study period; they conducted a longer period (almost 3 years). Regular and consistent availability of the necessary medicines is the topmost priority for any health sector. A shortage of pharmaceuticals adversely affects the quality of health care and the condition will be severe if stock out is prolonged.

Inadequate supply from the supplier, lack of information about $\mathrm{MCH}$ medicines and expiry were the mentioned reasons for stock out of WHO-prioritized $\mathrm{MCH}$ medicines. This reason was similar to the study conducted by Getahun et al. [36]. This might be because the pharmaceutical supply to public health facilities

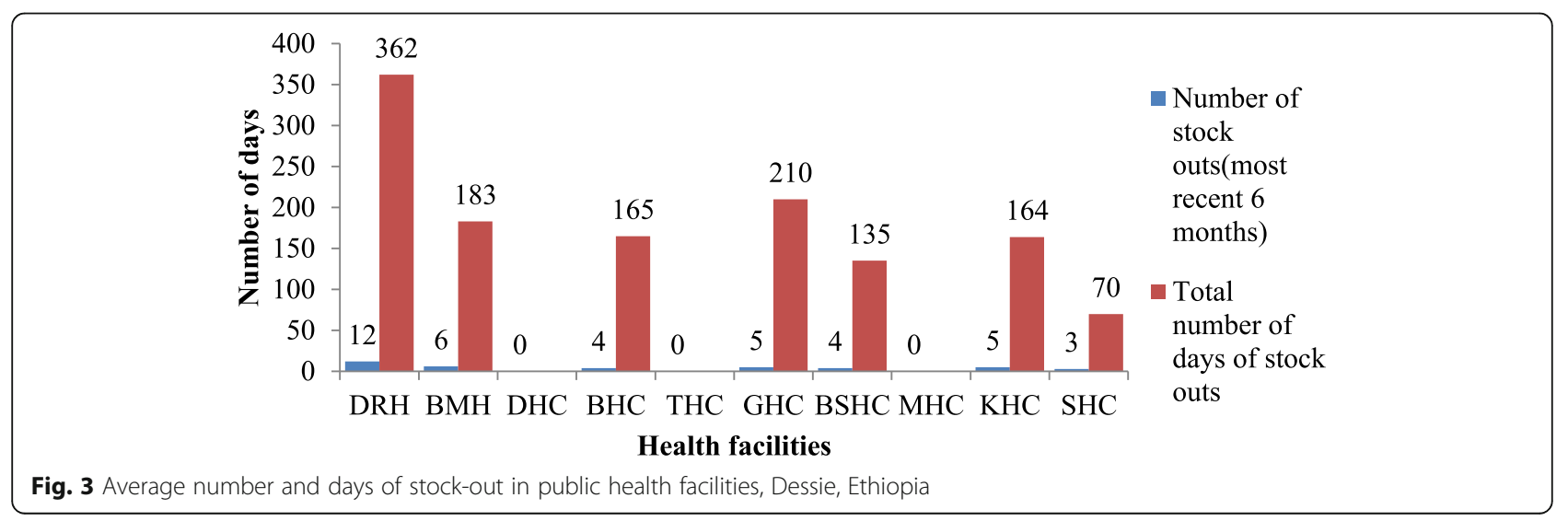


Table 2 Average number and stock out days for MCH priority medicines, Dessie, Ethiopia

\begin{tabular}{|c|c|c|c|}
\hline S.N & list of MCH medicines & $\begin{array}{l}\text { Number of stock outs } \\
\text { (most recent } 6 \text { months) }\end{array}$ & $\begin{array}{l}\text { Total number of days } \\
\text { of stock outs }\end{array}$ \\
\hline 1 & Amoxicillin: dispersible, scored tablets $250 \mathrm{mg}$ & 1 & 30 \\
\hline 2 & Ampicillin: powder for injection 500 mg & 5 & 165 \\
\hline 3 & Ceftriaxone: powder for injection $1 \mathrm{~g}$ & 7 & 204 \\
\hline 4 & Ceftriaxone: powder for injection 500 mg & 3 & 195 \\
\hline 5 & Gentamicin: injection 40 mg/ml(20 mg/mL) & 1 & 10 \\
\hline 6 & Morphine: granules injection 10 mg/mL & 1 & 15 \\
\hline 7 & Oxytocin: injection $10 \mathrm{IU}$ in 1-ml ampoule & 1 & 25 \\
\hline 8 & Sodium chloride: injectable solution $0.9 \%$ isotonic & 4 & 95 \\
\hline 9 & Sodium lactate compound: injectable (Ringer's lactate) & 4 & 58 \\
\hline 10 & Magnesium sulfate: injection 500 mg/ml in 10-ml mL Ampoule & 1 & 30 \\
\hline 11 & Calcium gluconate injection: $100 \mathrm{mg} / \mathrm{ml}$ in $10-\mathrm{ml} \mathrm{mL}$ ampoule & 1 & 60 \\
\hline 12 & Hydralazine: powder for injection 20 mg & 1 & 15 \\
\hline 13 & Methyldopa: tablet 250 mg & 3 & 90 \\
\hline 14 & Dexamethasone: injection 4 mg & 2 & 140 \\
\hline 15 & Tetanus vaccine & 1 & 7 \\
\hline 16 & Oral contraceptives (pack of 2) & 1 & 60 \\
\hline 17 & Intrauterine devices and barrier methods (e.g. condoms) & 2 & 90 \\
\hline
\end{tabular}

throughout the country is being managed by the same supplier [37] as a result of the lack of a strong information communication system between the supplier.

The mean average point availability in the overall health facility was $33.5 \%$, and on the day of the assessment, stock-outs of medicines were ampicillin $500 \mathrm{mg}$ injection, ceftriaxone $1 \mathrm{~g}$ injection, ceftriaxone $500 \mathrm{mg}$ injection sodium chloride injectable solution, methyldopa $250 \mathrm{mg}$ tablet, female condoms, and ringer lactate solution. This finding was lower than that of a study in
Malawi reported that the overall mean availability was $60 \%$ and stock-outs of at least one product on the day of the assessment [14]. This discrepancy was attributed to the expiry of medicines before use.

In the present study, the lowest-paid government worker in Dessie town unable to purchase the product to cover the full course of treatment like ceftriaxone $1 \mathrm{~g}$ injection, hydralazine $20 \mathrm{mg}$ injection, and tetanus antitoxin, which require more than daily wages. The results were lower than studies in China, where the affordability

Table 3 Affordability of WHO prioritize MCH medicines in public health facilities, Dessie, Ethiopia

\begin{tabular}{|c|c|c|c|c|}
\hline No & Condition & List of $\mathrm{MCH}$ medicines & Treatment schedule & $\begin{array}{l}\text { Days wages to pay } \\
\text { for treatment }\end{array}$ \\
\hline 1 & Pneumonia & Amoxicillin: dispersible, scored tablets 250 mg & $\begin{array}{l}25 \mathrm{mg} / \mathrm{kg}^{\mathrm{a}} 14.5 \mathrm{~kg} \text { PO BID } \\
\text { for } 7 \text { days }=21 \mathrm{cap}\end{array}$ & 0.38 \\
\hline 2 & severe Pneumonia & Ceftriaxone: powder for injection $1 \mathrm{~g}$ & $\begin{array}{l}80 \mathrm{mg} / \mathrm{kg}^{\mathrm{a}} 14.5 \mathrm{~kg} \text { IV daily } \\
\text { for } 10 \text { days }=12 \text { vial }\end{array}$ & 6.58 \\
\hline 3 & severe Pneumonia & Ceftriaxone: powder for injection 500 mg & $\begin{array}{l}80 \mathrm{mg} / \mathrm{kg}^{\mathrm{a}} 14.5 \mathrm{~kg} \text { IV daily } \\
\text { for } 10 \text { days }=24 \text { vial }\end{array}$ & 8.01 \\
\hline 4 & Neonatal sepsis & Gentamicin: injection 40 mg/mL(20 mg/ml) & $\begin{array}{l}5 \mathrm{mg} / \mathrm{kg}^{\mathrm{a}} 14.5 \mathrm{~kg} \text { IV daily for } \\
10 \text { days }=10 \mathrm{amp}\end{array}$ & 1.17 \\
\hline 5 & Diarrhea & ORS sachets of 11 , appropriate flavor & $75 \mathrm{ml} / \mathrm{kg}^{\mathrm{a}} 14.5 \mathrm{~kg}=2$ sachet & 0.32 \\
\hline 6 & Postpartum hemorrhage & Oxytocin: injection $10 \mathrm{IU}$ in $1-\mathrm{mL}$ ampoule & 10 units IM stat & 0.25 \\
\hline 7 & Postpartum hemorrhage & Sodium chloride: injectable solution $0.9 \%$ isotonic & $1000 \mathrm{ml}$ & 1.08 \\
\hline 8 & Postpartum hemorrhage & Sodium lactate compound: injectable (Ringer's lactate) & $1000 \mathrm{ml}$ & 1.22 \\
\hline 9 & Severe pre-eclampsia and eclampsia & Hydralazine: powder for injection 20 mg & 20 mg/ml IM BID daily & 5.02 \\
\hline 10 & Prevention of tetanus & Tetanus antitoxin & 10,000 IU IM after skin test & 3.45 \\
\hline
\end{tabular}

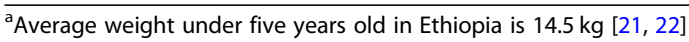




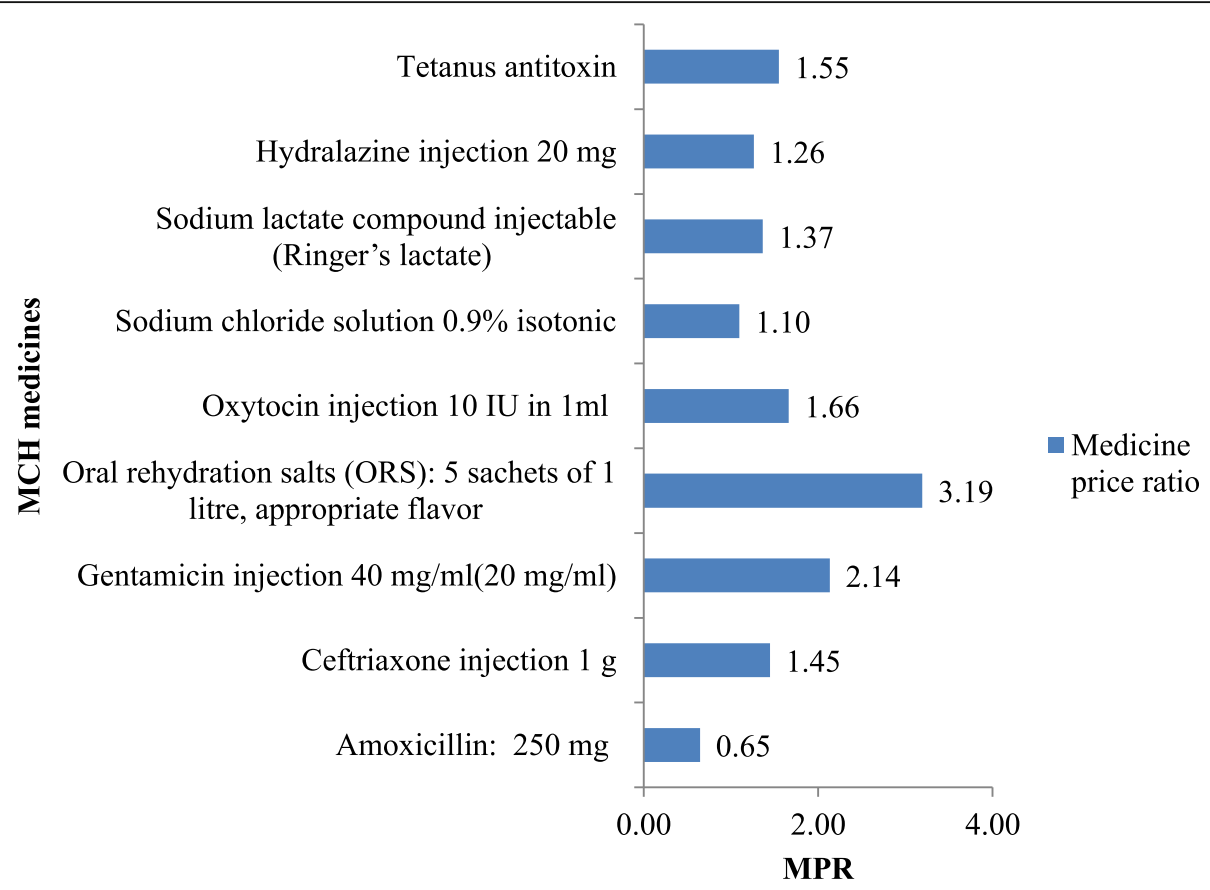

Fig. 4 MPR the WHO prioritizes MCH medicines in public health facilities, Dessie, Ethiopia

of amoxicillin $250 \mathrm{mg}$ for the treatment of severe pneumonia was 1.4 [38]. A study conducted by van Mourik $\mathrm{M}$ revealed that for treatment of infectious disease with ceftriaxone $1 \mathrm{~g}$ injection, 15 days wages required [39]. The lowest-paid government worker was unable to afford due to their lower financial income [20]. The rising out-of-pocket health spending continues to threaten the affordability of medical care [40, 41].

The MPR was 4 (55.5\%) and was considered to be high. The ORS sachets of 11 were 3.19 times greater, gentamycin injection was 2.14 times greater, and Amoxicillin $250 \mathrm{mg} 0.65$ times lower than international median prices. This was a higher MPR (1.53) as compared to the Sado E and Sufa A study [42]. Wang X et al. (2014) study revealed that the MPR for ORS was (2.22) and the MPR for amoxicillin (1.82) [43]. Such differences among studies might be due to price inflation of the dollar exchange rate and profit markup range added to retail patient prices for medicines. Some medicines supplied from donors without a price and this medicine, price setting are used for auditing purposes. Besides, high prices were more pronounced when purchasing done from private wholesales during stock out. Although the cost of health care services for $\mathrm{MCH}$, including WHO prioritize medicines was covered by the government, the burden still relies on the government. Catastrophic household health expenditure from out-ofpocket expenditure on medicines could plunge patients into poverty [44].
The availability and affordability of medicines with reasonable prices in public health facilities have strong clinical implications for reducing maternal, newborn, child morbidity, and mortality. This study has significant for the government, stakeholders, managers, and policymakers to develop national regulations and strategies to enhance access to $\mathrm{WHO}$ priority $\mathrm{MCH}$ medicines for public health facilities.

The point and period availability formula consider the availability of medicines ranging from low to overstock regardless of health institutions need. Nevertheless, in the real world, the availed $\mathrm{WHO}$ prioritize $\mathrm{MCH}$ medicines might not be sufficient and do not show how much amount of medicines are adequate. The affordability formula failed to incorporate the wages of people in the informal sector who were below the salary income of the government. Moreover, in the MPR calculation, the international price used for comparison was the list of medicine by management science for the health 2015 version and does not update yet, and it has limitations in revealing the MPR ratio at present time. The $\mathrm{WHO} / \mathrm{HAI}$ price project recommended collecting the price on targeted medicines at state or provincial the result was specific to the surveyed province and thus cannot be generalized to the country.

\section{Conclusion}

The average mean availability of $\mathrm{WHO}$ prioritized $\mathrm{MCH}$ medicines in the past 6 months and point mean availability was very low and a high number of stock-outs. 
One-third of WHO prioritized medicines were completely unmanaged in all health facilities. From the WHO priority list of medicines, some of the products were unaffordable. Improving availability and strict inventory control are recommended to have a steady supply of these essential medicines to improve the quality of health services.

\section{Abbreviations}

HAl: Health Action International; MCH: Maternal and child health; MPR: Median Price Ratio; ORS: Oral rehydration salt; WHO: World Health Organization

\section{Acknowledgements}

The authors would like to acknowledge Mr. Mustefa Negash and data collectors: Abraham Mekonnen and Samson Birhanu for their commitment in the data collection process.

\section{Declarations}

Not applicable.

\section{Authors' contributions}

$\mathrm{ADH}$ analyzed and wrote the manuscript. SAM proofread the manuscript. All authors approved the final version of this manuscript.

\section{Funding}

None.

\section{Availability of data and materials}

All data generated or analyzed during this study are included in this published article.

\section{Ethics approval and consent to participate}

The ethical issue of the research was approved by the Ethics Review Committee of Pharmacy Department, Wollo University (CMHS 075/11), and an official letter of cooperation was written from the Dessie health department to all public and private hospital found in Dessie town where the study was conducted (3/240/2011). During the data collection process, the information collected from all health facilities was kept confidential. The name of the health facilities was coded in the data collection format. Written informed consent was obtained from all health facilities before assessing by the checklist.

\section{Consent for publication}

None.

\section{Competing interests}

The authors declare that they have no competing interests.

\section{Author details}

${ }^{1}$ Department of Pharmacy, Dessie Health Science College, Dessie, Ethiopia. ${ }^{2}$ Department of Pharmacy, College of Health Science, Wollo University, Dessie, Ethiopia.

Received: 6 April 2020 Accepted: 6 September 2020 Published online: 11 September 2020

\section{References}

1. Margolis L, Kotch J. Tracing the historical foundations of maternal and child health to contemporary times. Matern Child Health. 2012;25:11.

2. World Health Organization. Equitable access to essential medicines: a framework for collective action. World Health Organization; 2004. Available at: https://apps.who.int/iris/bitstream/handle/10665/68571/WHO_EDM_2 004.4 rus.pdf.

3. Hill S, Yang A, Bero L. Priority medicines for maternal and child health: a global survey of national essential medicines lists. PLoS One. 2012;7(5): e38055.

4. Dieleman JL, Campbell M, Chapin A, Eldrenkamp E, Fan W. Haakenstad A Kates J, Li Z, Matyasz T, Micah A, Reynolds A. Future and potential spending on health 2015-40: development assistance for health, and government, prepaid private, and out-of-pocket health spending in 184 countries. Lancet. 2017;389(10083):2005-30

5. Leisinger KM, Garabedian LF, Wagner AK. Improving access to medicines in low and middle income countries: corporate responsibilities in context. Southern Med Rev. 2012:5(2):3.

6. World Health Organization. Workshop on ensuring access to priority medicines for mothers and children, Manila, Philippines, 15 to 17 august 2011: report. Manila: WHO Regional Office for the Western Pacific; 2011.

7. UNICEF. State of the World's Children: Celebrating 20 Years of the Convention on the Rights of the Child. Unicef; 2009. Available at: https:// books.google.com/books?hl=en\&lr=\&id=TsSsUZ990HUC\&oi=fnd\&pg=PA1 $\& d q=7 . \% 09 U N I C E F . .+$ State+of+the+World\%27s+Children:+Celebrating+20+ Years+of+the+Convention+on+the+Rights+of+the+Child.+Unicef $\% 3 \mathrm{~B}+2$ 009.\&ots=uWzXH_Hkve\&sig=aQvjcp5NVhT2O8Bu1xiel9QK6lg.

8. Bryce J, Requejo JH. Tracking progress in maternal, newborn and child survival: the 2008 report. New York: UNICEF; 2008.

9. World Health Organization. World health statistics 2016: monitoring health for the SDGs sustainable development goals. World Health Organization; 2016. Available at: https://books.google.com/books?hl=en\&lr=\&id=-A4 LDgAAQBAJ\&oi=fnd\&pg=PP1\&dq=9.\%09World+Health+Organization.+ World+health+statistics+2016:+monitoring+health+for+the+SDGs+ sustainable+development+goals.+World+Health+Organization\%3B+2016+ Jun+8.\&ots=dbql3RcowB\&sig=ZA91OeUeORkGBJZ60Zam6IKSDgg.

10. World Health Organization, World Health Organization. Ageing, Life Course Unit. WHO global report on falls prevention in older age. World Health Organization; 2008. Available at: https://books.google.com/books?hl=en\&lr= \&id=ms9o2dvfaQkC\&oi=fnd\&pg=PA1\&dq=10.\%09World +Health+ Organization,+World+Health+Organization.+Ageing,+Life+Course+Unit.+ WHO+global+report+on+falls+prevention+in+older+age.+World+Health+ Organization\%3B+2008.\&ots=5KFOLGWM_X\&sig=GLc8Ub3W8zytoPb2 srZfwrPqYo.

11. United Nations Development Group, United Nations. Statistical Division. Indicators for monitoring the millennium development goals: definitions, rationale, concepts and sources. United Nations Publications; 2003. Available at: http://mdgs.un.org/unsd/mdg/Resources/Attach/Indicators/ HandbookEnglish.pdf.

12. Mhlanga BS, Suleman F. Price, availability and affordability of medicines. Afr J Prim Health Care Fam Med. 2014:6(1):1-6.

13. Zarocostas J. Better access to drugs could save 10 million lives a year, says UN expert. BMJ. 2007:335(7621):635.

14. Chandani Y, Noel M, Pomeroy A, Andersson S, Pahl MK, Williams T. Factors affecting availability of essential medicines among community health workers in Ethiopia, Malawi, and Rwanda: solving the last mile puzzle. Am J Trop Med Hyg. 2012:87(5 Suppl):120-6.

15. Central Statistics Agency Ethiopia. Central statistics agency of Ethiopia report of the population and housing census. 2007. Available at: http:// www.csa.gov.et/census-report/complete-report/census-2007.

16. World Health Organazation. Priority life-saving medicines for women and children. 2012. Available at: https://www.who.int/reproductivehealth/ publications/general/emp mar2012.1/en/.

17. Gelders S, Ewen M, Noguchi N, Laing R. Price, availability and affordability: an international comparison of chronic disease medicines. Cairo: World Health Organization and Health Action International; 2006.

18. Management Sciences for Health. International medical products price guide, 2015 edition. 2016. Available at: http://apps.who.int/medicinedocs/ documents/s21982en/s21982en.pdf.

19. Auditable Pharmaceutical Transactions and Services Trainers' Guide, last version. 2018. Available at https:// www.biorxiv.org/content/biorxiv/early/2 018/07/26/378000.full.pdfT.

20. Robertson J, Forte G, Trapsida JM, Hill S. What essential medicines for children are on the shelf? Available at: https://www.scielosp.org/article/ bwho/2009.v87n3/231-237.

21. Ethiopia CSA. Ethiopia demographic and health survey. Central statistical agency. Central statistical Agency of Ethiopia: Addis Ababa, Ethiopia; 2012

22. World Health Organization. Child growth standards. Geneva: World Health Organization. Available at: https://www.who.int/childgrowth/en/.

23. Ranabhat $\mathrm{CL}$, Atkinson J, Park MB, Kim CB, Jakovljevic M. The influence of universal health coverage on life expectancy at birth (LEAB) and healthy life expectancy (HALE): a multi-country cross-sectional study. Front Pharmacol. 2018;9:960. 
24. Nyanwura EM, Esena RK. Essential medicines availability and affordability: a case study of the top ten registered diseases in Builsa District of Ghana. Int J Sci Technol Res. 2013;2(8):208-19.

25. Abrha S, Tadesse E, Atey TM, Molla F, Melkam W, Masresha B, Gashaw S, Wondimu A. Availability and affordability of priority life-saving medicines for under-five children in health facilities of Tigray region, northern Ethiopia. BMC Pregnancy Childbirth. 2018;18(1):464.

26. Sautenkova N, Ferrario A, Bolokhovets G, Kanavos P. Availability and affordability of medicines and assessment of quality systems for prescription of medicines in the Republic of Moldova; 2012.

27. Prinja S, Bahuguna P, Tripathy JP, Kumar R. Availability of medicines in public sector health facilities of two north Indian states. BMC Pharmacol Toxicol. 2015;16(1):43.

28. Bazargani YT, Ewen M, de Boer A, Leufkens HG, Mantel-Teeuwisse AK. Essential medicines are more available than other medicines around the globe. PLoS One. 2014;9(2):e87576.

29. Anson A, Ramay B, de Esparza AR, Bero L. Availability, prices and affordability of the World Health Organization's essential medicines for children in Guatemala. Glob Health. 2012;8(1):22.

30. Federal Democratic Republic of Ethiopia. Ministry of Health. Health Sector Development Program IV. Addis Ababa, Ethiopia: Ethiopian Central Statistical Authority; 2010.

31. Kondro W. Priority medicines for maternal and child health. Can Med Assoc J. 2011;183(7):E371

32. Jakovljevic MB. The key role of the leading emerging BRIC markets in the future of global health care. Serbian J Exp Clin Res. 2014;15(3):139-43.

33. Fentie M, Fenta A, Moges F, Oumer H, Belay S, Sebhat Y, Atinafu T, Mekonnen T, Somasundaram J. Availability of essential medicines and inventory management practice in primary public health facilities of Gondar town, north West Ethiopia. J PharmaSciTech. 2015:4(2):54-6.

34. Kibira D, Kitutu FE, Merrett GB, Mantel-Teeuwisse AK. Availability, prices and affordability of UN Commission's lifesaving medicines for reproductive and maternal health in Uganda. J Pharm Policy Pract. 2017;10(1):1-8.

35. Wagenaar BH, Gimbel S, Hoek R, Pfeiffer J, Michel C, Manuel JL, Cuembelo F, Quembo T, Afonso P, Gloyd S, Sherr K. Stock-outs of essential health products in M ozambique-longitudinal analyses from 2011 to 2013. Tropical Med Int Health. 2014;19(7):791-801.

36. Getahun W, Tadeg H, Ejigu E, Korra A. Health facility assessment on availability of the 13 reproductive, maternal, newborn, and child health commodities prioritized by the UN Commission on life-saving Commodities for Women and Children. United States Agency for International Development: Arlington; 2015.

37. Federal Democratic Republic of Ethiopia, Ministry of Health. Country Implementation Plan for Prioritized Life-Saving Commodities for Women and Children. Addis Ababa, Ethiopia: Federal Ministry of Health; 2013. Available at: http://supplypromises.org/wp-content/uploads/2014/09/ ETHIOPIA-UNCOLSC-.pdf.

38. Yang H, Dib HH, Zhu M, Qi G, Zhang X. Prices, availability and affordability of essential medicines in rural areas of Hubei Province, China. Health Policy Plan. 2010;25(3):219-29.

39. Van Mourik MS, Cameron A, Ewen M, Laing RO. Availability, price and affordability of cardiovascular medicines: a comparison across 36 countries using WHO/HAl data. BMC Cardiovasc Disord. 2010;10(1):25.

40. Jakovljevic MM, Ogura S. Health economics at the crossroads of centuriesfrom the past to the future. Front Public Health. 2016:4:115.

41. Jakovljevic MM. Comparison of historical medical spending patterns among the BRICS and G7. J Med Econ. 2016;19(1):70-6.

42. Sado E, Sufa A. Availability and affordability of essential medicines for children in the Western part of Ethiopia: implication for access. BMC Pediatr. 2016;16(1):40.

43. Wang $X$, Fang $Y$, Yang $S$, Jiang M, Yan $K$, Wu L, Lv B, Shen Q. Access to paediatric essential medicines: a survey of prices, availability, affordability and price components in Shaanxi Province, China. PLoS One. 2014;9(3): e90365.

44. Jakovljevic M, Jakab M, Gerdtham U, McDaid D, Ogura S, Varavikova E, Merrick J, Adany R, Okunade A, Getzen TE. Comparative financing analysis and political economy of noncommunicable diseases. J Med Econ. 2019; 22(8):722-7.

\section{Publisher's Note}

Springer Nature remains neutral with regard to jurisdictional claims in published maps and institutional affiliations.

\section{Ready to submit your research? Choose BMC and benefit from:}

- fast, convenient online submission

- thorough peer review by experienced researchers in your field

- rapid publication on acceptance

- support for research data, including large and complex data types

- gold Open Access which fosters wider collaboration and increased citations

- maximum visibility for your research: over $100 \mathrm{M}$ website views per year

At $\mathrm{BMC}$, research is always in progress.

Learn more biomedcentral.com/submissions 